\title{
OSCILLATION CRITERIA FOR HALF-LINEAR DIFFERENTIAL EQUATIONS WITH $p(t)$-LAPLACIAN
}

\author{
YUTAKA SHOUKAKU
}

Abstract. This paper presents suffient conditions for oscillation of solutions of half-linear differential equations with $p(t)$-Laplacian. As an application of generalized Riccati-type inequality, some new oscillation theorems are established.

Mathematics subject classification (2010): 34K11, 35B05, 35R10.

Keywords and phrases: $p(t)$-Laplacian, oscillation theory, half-linear.

\section{REFERENCES}

[1] T. AdAmOwicz, P. HÄstÖ, Mapping of finite distribution and PDF with nonstandard growth, Int. Math. Res. Not. IMRN, (2010), 1940-1965.

[2] T. AdAmowicz, P. Hëstö, Harnak's inequality and the strong $p(\cdot)$-Laplacian, J. Differential Equations, 250 (2011), 1631-1649.

[3] L. Diening, P. HARJulehto, P. Hëstö, M. RŮŽIČKa, Lebesgue and Sobolev spaces with variable exponents, Lecture Notes in Mathematics, vol. 2017, Springer-Verlag, Heidelberg, 2011.

[4] P. HäST ö, The $p(x)$-Laplacian and applications, J. Analysis, 15 (2007), 53-62.

[5] P. Harjulehto, P. Hästö, Ú. Lê And M. NuORTiO, Overview of differential equations with non-standard growth, Nonlinear Anal., 72 (2010), 4551-4574.

[6] Q. H. ZHANG, Oscillatory property of solutions for $p(t)$-Laplacian equations, J. Inequal. Appl., 2007 (2007), 1-8.

[7] Y. SAHINER AND A. ZAFER, Oscillation of nonlinear elliptic inequlities with $p(x)$-Laplacian, Complex Vriables and Elliptic Equations, (2012), 1-10.

[8] Y. SAHINeR AND A. ZAFER, Oscillation of $p(x)$-Laplacian elliptic inequalities with mixed variable exponents, Mathematical Inequalities \& Applications, (2013), 947-961.

[9] H. Us ami, Some oscillation theorem for a class of quasilinear elliptic equations, Ann. Mat. Pura Appl., 175 (1998), 277-283.

[10] N. YoshIDA, Oscillation criteria for half-linear elliptic inequalities with $p(x)$-Lapacians via Riccati method, Nonlinear Anal., 74 (2011), 2563-2575.

[11] N. YoshIDA, Picone-type inequality and sturmian comparison theorems for quasilinear elliptic operators with $p(x)$-Laplacians, Electronic J. Diff. Equ., 2012 (2012), 1-9. 